\title{
Prosthodontic Management of Single Anterior Missing Tooth with Immediate Loading Implant Using Leukocyte-Platelet-Rich Fibrin
}

\author{
Prashanti Wahengbam ${ }^{1}$ Tarun Kalra ${ }^{1}$ Manjit Kumar ${ }^{1}$ Ajay Bansal ${ }^{1}$ Ramandeep Singh ${ }^{1}$ \\ 1 Department of Prosthodontics, Bhojia Dental College and Hospital, \\ Baddi, Himachal Pradesh, India \\ Address for correspondence Manjit Kumar, MDS, Department of \\ Prosthodontics, Bhojia Dental College and Hospital, Baddi 173205, \\ Himachal Pradesh, India (e-mail: manjitkiran@yahoo.co.in).
} Dent J Adv Stud 2022;10:107-110.

\begin{abstract}
Keywords

- dental implants

- immediate loading

- leukocyte-plateletrich fibrin
\end{abstract}

Immediate loading of dental implant in the anterior tooth region has been a growing trend and eliminates the compromised esthetics, function, discomfort, and inconvenience associated with traditional two-stage implant procedures. This case report presents the clinical application of implant placement with immediate loading using leukocyte-platelet-rich fibrin (L-PRF) in the anterior esthetic region.The implant was planned to rehabilitate in the anterior missing tooth region. As per the patient's desire, the implant was immediately loaded and L-PRF membrane was placed around the implant under local anesthesia on the day of surgery.The use of L-PRF for the maintenance of crestal bone and soft tissue at the implant sites provided an adequate clinical condition for better esthetics.

\section{Introduction}

The important requirement of successful osseointegration is prolonged healing period after the surgical closure. According to Branemark, after treating a number of patients with different defects in the bone it was observed that 3 to 6 months of healing period was necessary. ${ }^{1}$ According to Szmukler-Moncler et al, ${ }^{2}$ early loading can be done without effecting the successful osseointegration.

In modern era, because of esthetics, function, and discomfort of being edentulous, two-stage implant procedure has been taken over by immediate loading of implants. ${ }^{3}$

Single titanium dental implant-retained tooth restorations have demonstrated to be a both predictable and successful treatment alternative in the long-term perspective. $^{4}$

Many clinicians recommended immediate placement of temporary crowns with or without loading to overcome more working time and patient discomfort. ${ }^{5,6}$

published online July 29, 2021
DOI https://doi.org/

10.1055/s-0041-1733819. ISSN 2321-1482.
Growth factors and biomaterials have been traditionally used to increase healing of both hard and soft tissues around implant. A second generation of platelet concentrates, leukocyte-platelet-rich fibrin (L-PRF) increases wound healing in both soft and hard tissues at implant osteotomy site. ${ }^{7}$

For better esthetic and function in treatment by implants L-PRF is used at the osteotomy site. Matrix of PRF is tetragonal structure having biodegradable scaffold made up of cytokines, platelets, and stem cells and this guides the epithelial cell migration to its surface and results in the growth of microvascularization. ${ }^{8,9}$

Some authors had concluded that PRF is a biomaterial that helps in healing which leads to bone and soft tissue growth, without causing inflammation. This along with bone grafts, promotes hemostasis, bone growth, and maturation. ${ }^{10}$

This article presents a case report on the immediate loading of an implant-supported, single tooth restoration in the anterior region with the use of L-PRF without graft. (c) 2021. Bhojia Dental College and Hospital affiliated to Himachal Pradesh University. All rights reserved.

This is an open access article published by Thieme under the terms of the Creative Commons Attribution-NonDerivative-NonCommercial-License, permitting copying and reproduction so long as the original work is given appropriate credit. Contents may not be used for commercial purposes, or adapted, remixed, transformed or built upon. (https://creativecommons.org/ licenses/by-nc-nd/4.0/)

Thieme Medical and Scientific Publishers Pvt. Ltd., A-12, 2nd Floor, Sector 2, Noida-201301 UP, India 


\section{Case Presentation}

A 34-year-old male patient in a good health condition reported to the Postgraduate Department of Prosthodontics, Bhojia Dental College and Hospital, Baddi, Himachal Pradesh, India, with the chief complaint of missing tooth in the anterior region and wanting to replace with a fixed prosthesis immediately (-Figs. 1 and 2). Treatment options were discussed with the patient and treatment was planned for implant placement with immediate loading on the day of surgery.

The patient opted for implant treatment as he did not want to sacrifice adjacent tooth structure for crown preparation and wants his tooth to be placed on the day of surgery. The patient had no relevant past medical history. No alveolar height loss was detected. Important parameters, such as quality and quantity of soft and hard tissues, were evaluated and the patient was informed that he was an ideal candidate for implant placement and immediate loading of dental implants.

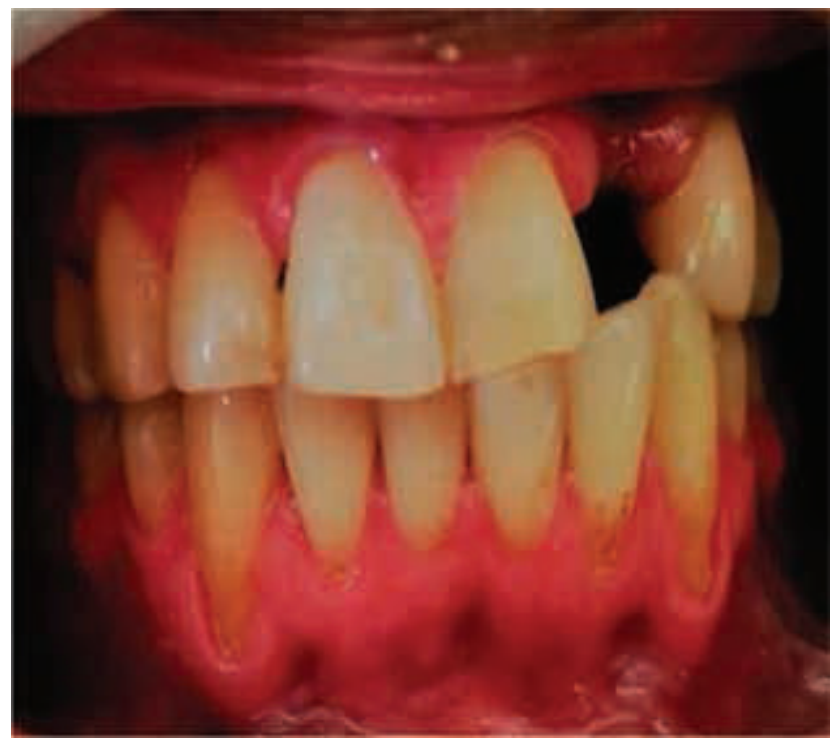

Fig. 1 Intraoral view missing 21.

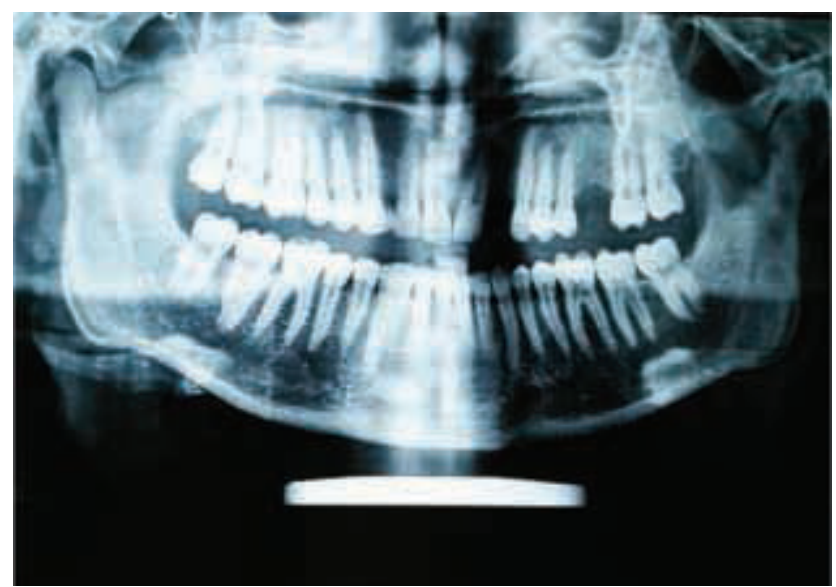

Fig. 2 Preoperative orthopantomogram (OPG).

\section{Surgical Procedure}

After raising the full thickness flap different sizes of drills were used to prepare the osteotomy site. An Adin titanium implant (Touareg S, Adin, Israel) was inserted with primary stability of 35 to $40 \mathrm{Ncm}$ ( - Fig. 3). In this, L-PRF membrane was placed around the implant to preserve and maintain the soft tissue profile.

\section{Preparation of the L-PRF Membrane}

From antecubital vein of the patient $10 \mathrm{~mL}$ of blood was taken and clot was obtained after rotating it at 3,000 revolutions per minute for 13 minutes in centrifugal machine (PRF Duo). With the help of gauge piece the clot was converted in to L-PRF membrane. Because of network, growth factors keep on promoting tissue growth for longer period of time ( - Fig. 4).

After ensuring the stabilization of the membrane, the final wash of the surgical site using residual plasma solution was done. For checking the positional accuracy intraoral periap-

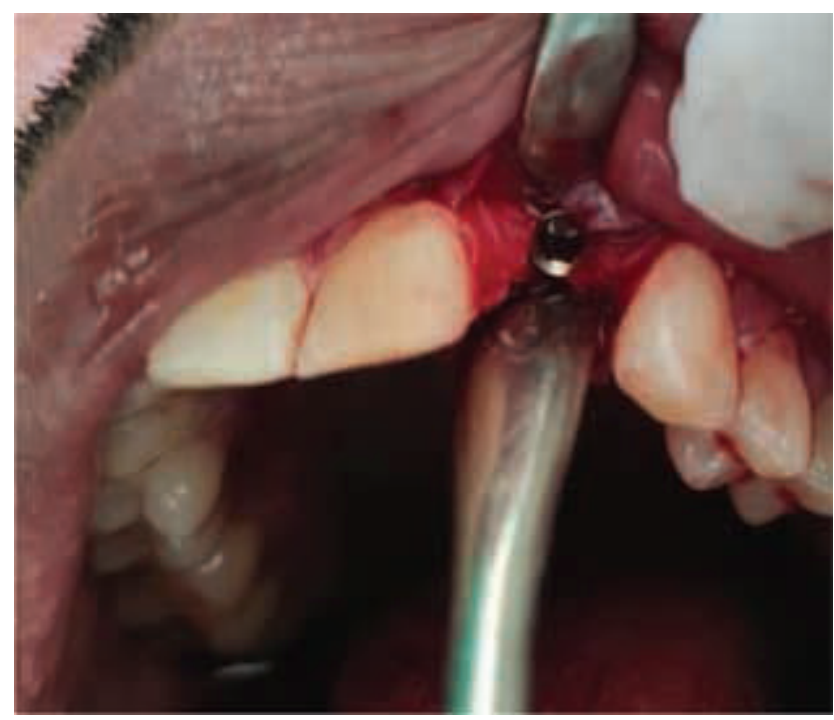

Fig. 3 Implant in situ.

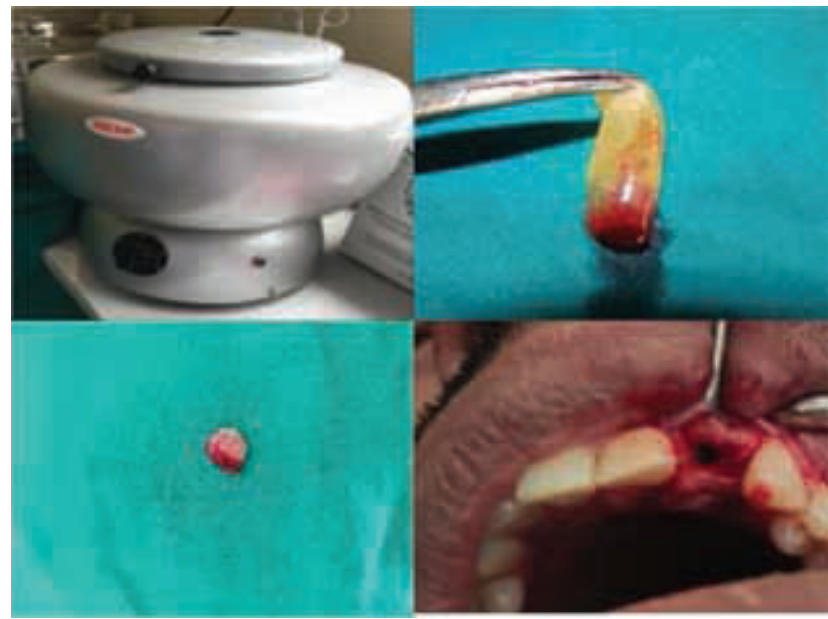

Fig. 4 Platelet-rich fibrin (PRF) membrane preparation and placement. 
ical radiograph was taken (-Fig. 5). Abutment was modified to create space and parallelism and attached to the implant body. For functional and esthetic requirements provisional acrylic crown was placed in the patient's mouth on the very same day. Occlusal contacts on it were eliminated in all lateral and excursive movements. The temporary restoration was luted using provisional cement (Temp Bond; Kerr, United States) (-Fig. 6).

Postoperative management: Patient was advised soft diet and mouthwash rinse with $0.12 \%$ chlorhexidine gluconate twice daily. Patient was prescribed antibiotic, analgesic, and
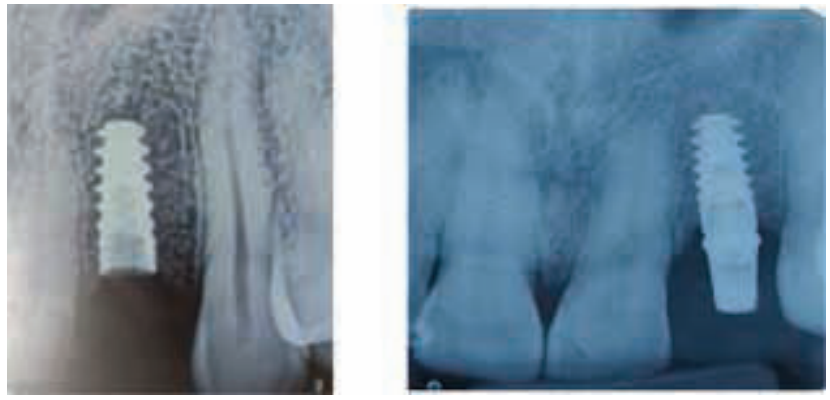

Fig. 5 Radiographs: postsurgical and after 6 months.

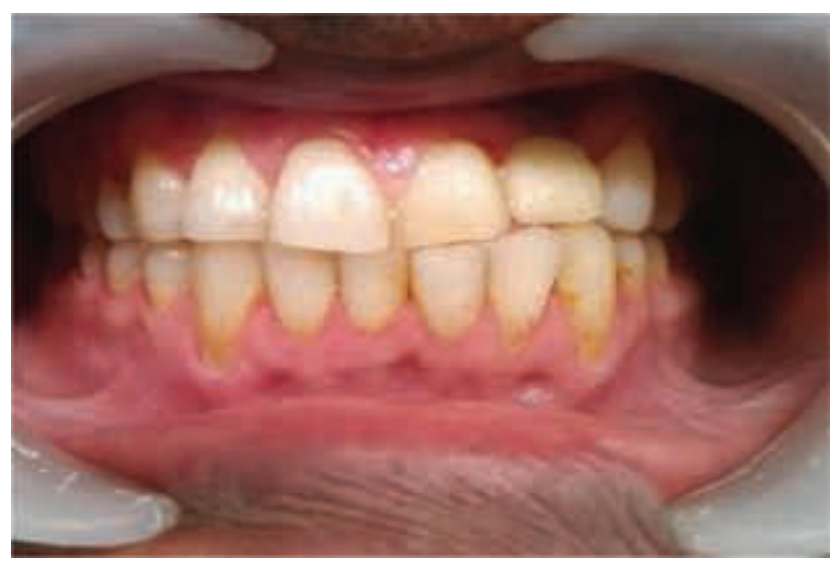

Fig. 6 Provisional restoration with respect to 21.

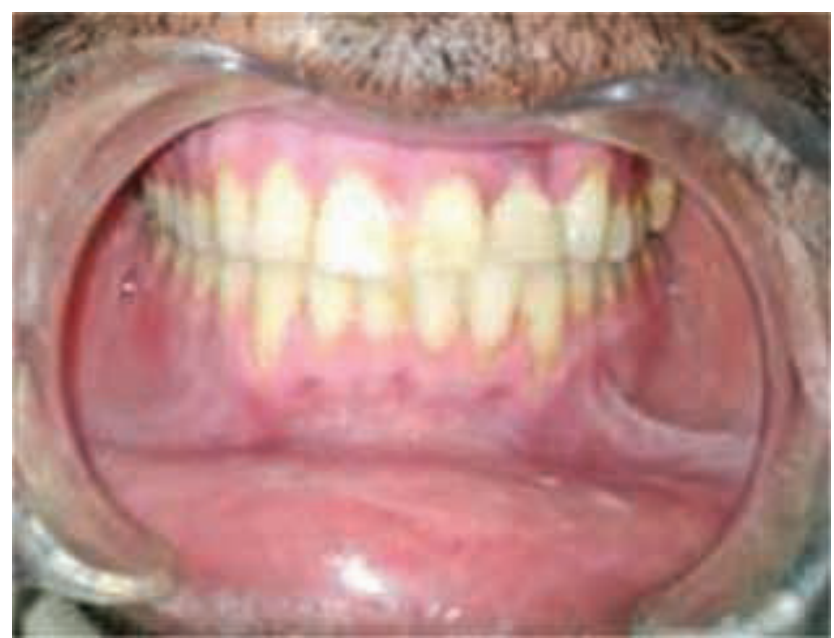

Fig. 7 Final porcelain-fused-to-metal (PFM) crown with respect to 21. anti-inflammatory for 5days. Patient was fallowed up after 1 week.

Final prosthesis and follow-up: The patient was recalled for the definitive prosthesis after the healing period of 6 months. A good osseointegration was seen in radiograph. A closedtray single-phase impression polyether (3M ESPE India [Soft]) impression was made. The temporary crown was replaced with a definitive prosthesis (-Fig. 7). The healing period was without any complications of implant mobility or peri-implant infection.

\section{Discussion}

The patient with a missing left lateral incisor was treated with an implant with PRF associated with immediate loading.

Growth factors are biologically active polypeptides that help in the healing process. These are very helpful in regenerative implantology. Commercially available bioactive materials are very costly so platelet-based preparations from the patient's own blood are gaining popularity these days.

In the present study, PRF, a platelet concentrate, was used as a source of growth factors to accelerate the initial stages of wound healing. ${ }^{11}$

L-PRF is a second generation of autologous platelet concentration and a fibrin mesh consisting of leukocytes, growth factors, proteins, and cytokines.

The architecture of L-PRF consists of trimolecules, and due to a slow polymerization of the platelet concentrate and no heterologous thrombin, there is production of a flexible fibrin network, gradual release of growth factors, and leukocytes migration. The fibrin membrane protects the surgical site and promotes healing mechanisms of angiogenesis. ${ }^{7}$

The fibrin structure is strong in L-PRF as compared to PRP and plasma rich in growth factors and there is no need of modification with bovine thrombin or anticoagulants. There is slow release of growth factor from L-PRF at least for 28 days which helps in better environment healing phase. This growth factor because of the nature of fibrin keeps doing its activity for a longer period of time and promotes faster tissue regeneration. ${ }^{12,13}$

PRF has the property of increasing tissue cicatrization during neovascularization, leading to faster tissue remodeling without any complications of the wound healing like pain and pus formation. In dentistry PRF is widely used in the treatment of gingivitis, periodontal defects, oral lesions, and palatal wound closure. PRF also helps in proliferation of dermal fibroblasts, gingival fibroblasts, and keratinocytes which helps in the synthesis of extracellular matrix collagen. This prevents ingrowth of bacteria into wound and promotes healing. ${ }^{14}$

For prevention of gingival tissue changes and in order to achieve emergence profile, temporary and final prostheses should be well-finished with concave contour. Immediate nonfunctional loading preserves gingival architecture, decreases time between surgery and restorative phase, reduces morbidity, reduces costs, and improves patient's comfort and satisfaction. ${ }^{5}$ 


\section{Conclusion}

In the present case, implant was successfully placed in the anterior region. PRF maintains the health of bone and soft tissue around the implant for better esthetics and postoperative healing. Clinically and radiographically after 6 months there was satisfactory preservation of marginal bone and peri-implant soft tissue condition as well as excellent esthetic rehabilitation for better prognosis in terms of esthetics and acceptance of the patient.

\section{Conflict of Interest \\ None declared.}

\section{References}

1 Attard NJ, Zarb GA. Immediate and early implant loading protocols: a literature review of clinical studies. J Prosthet Dent 2005; 94(03):242-258

2 Szmukler-Moncler S, Salama H, Reingewirtz Y, Dubruille JH. Timing of loading and effect of micromotion on bone-dental implant interface: review of experimental literature. J Biomed Mater Res 1998;43(02):192-203

3 Siddiqui AA, O'Neal R, Nummikoski Pet al.Immediate loading of single-tooth restorations: one-year prospective results. J Oral Implantol 2008;34(04):208-218

4 Ericsson I, Nilson H, Lindh T, Nilner K, Randow K. Immediate functional loading of Brånemark single tooth implants. An 18 months' clinical pilot follow-up study. Clin Oral Implants Res 2000;11(01):26-33

5 Ariano V, Mancini M, Cardi A, Condò R, Cerroni L, Pasquantonio G. Immediate Nonfunctional Loading of Two Single-Maxillary Postextractive Implants: 6-Year Postloading Results of Two Case Reports. Case Reports in Dentistry. London, UK: Hindawi Publishing Corporation 2016:1-7
6 Lindeboom JA, Frenken JW, Dubois L, Frank M, Abbink I, Kroon FH. Immediate loading versus immediate provisionalization of maxillary single-tooth replacements: a prospective randomized study with BioComp implants. J Oral Maxillofac Surg 2006;64(06): 936-942

7 Marenzi G, Riccitiello F, Tia M, di Lauro A, Sammartino G. Influence of leukocyte- and platelet-rich fibrin (L-PRF) in the healing of simple postextraction sockets: a split-mouth study. BioMed Res Int 2015;2015:369273

8 Dohan DM, Choukroun J, Diss Aet al.Platelet-rich fibrin (PRF): a second-generation platelet concentrate. Part I: technological concepts and evolution. Oral Surg Oral Med Oral Pathol Oral Radiol Endod 2006;101(03):e37-e44

9 Miron RJ, Fujioka-Kobayashi M, Bishara M, Zhang Y, Hernandez M, Choukroun J. Platelet-rich fibrin and soft tissue wound healing: a systematic review. Tissue Eng Part B Rev 2017;23 (01):83-99

10 Fujioka-Kobayashi M, Miron RJ, Hernandez M, Kandalam U, Zhang Y, Choukroun J. Optimized platelet-rich fibrin with the low-speed concept: growth factor release, biocompatibility, and cellular response. J Periodontol 2017;88(01):112-121

11 S. Medikeri R, Meharwade V, M. Wate P, V. Lele S. Effect of PRF and allograft use on immediate implants at extraction sockets with periapical infection -clinical and cone beam CT findings. Bull Tokyo Dent Coll 2018;59(02):97-109

12 Cortese A, Pantaleo G, Borri A, Caggiano M, Amato M. Platelet-rich fibrin (PRF) in implant dentistry in combination with new bone regenerative technique in elderly patients. Int J Surg Case Rep 2016;28:52-56

13 Sehgal M, Puri L, Yadav Set al.Immediate dental implants enriched with L-PRF in the esthetic zone. Case Rep Dent 2018; 2018:9867402

14 Cui A, Zhou J, Mudalal Met al.Soft tissue regeneration around immediate implant placement utilizing a platelet-rich fibrin membrane and without tightly flap closure: two case reports. Medicine (Baltimore 2020;99(40):e22507 